\title{
Screening and identification of potential target genes in head and neck cancer using bioinformatics analysis
}

\author{
FUHAI CHEN, ANYUAN ZHENG, FEN LI, SILU WEN, SHIMING CHEN and ZEZHANG TAO \\ Department of Otolaryngology-Head and Neck Surgery, Renmin Hospital of Wuhan University, \\ Wuhan, Hubei 430060, P.R. China
}

Received September 20, 2018; Accepted June 14, 2019

DOI: $10.3892 / \mathrm{ol} .2019 .10616$

\begin{abstract}
Head and neck cancer (HNC) is the sixth most common cancer worldwide. Recent studies on the pathogenesis of HNC have identified some biochemical associations of this disease, but the molecular mechanisms are not clear. To explore the genetic alterations in head and neck tumors, to identify new high-specificity and high-sensitivity tumor markers, and to investigate potentially effective therapeutic targets, in silico methods were used to study HNC. The GSE58911 microarray dataset was downloaded from the Gene Expression Omnibus online database to identify potential target genes in the carcinogenesis and progression of HNC. Differentially expressed genes (DEGs) were identified and functional enrichment analysis was performed. In addition, a protein-protein interaction network was also constructed, and gene analysis was undertaken using Search Tool for the Retrieval of Interacting Genes and Cytoscape. A total of 648 differentially expressed genes were identified. Kyoto Encyclopedia of Genes and Genomes pathway and Gene Ontology functional enrichment analysis of DEGs included muscle system process, extracellular matrix organization, actin binding, structural molecule activity, structural constituent of muscle, extracellular region part, ECM-receptor interaction, amoebiasis, focal adhesion, drug metabolism-cytochrome $\mathrm{P} 450$, and chemical carcinogenesis. There were 26 hub genes identified and biological process analysis revealed that these genes were mainly enriched in extracellular matrix organization, serine-type endopeptidase activity, extracellular matrix, and complement and coagulation cascades. Survival analysis revealed that interleukin (IL)-8 (C-X-C motif chemokine ligand 8), IL1B, and serpin family A member 1 may be involved in the carcinogenesis of HNC.
\end{abstract}

Correspondence to: Dr Zezhang Tao, Department of Otolaryngology-Head and Neck Surgery, Renmin Hospital of Wuhan University, 99 Zhangzhidong Road, Wuchang, Wuhan, Hubei 430060, P.R. China

E-mail: taozezhang@163.com

Key words: head and neck cancer, differentially expressed genes, protein-protein interaction network, potential target genes, functional enrichment analysis
In summary, the DEGs and hub genes identified in the present study may increase understanding of the molecular mechanisms of development of HNC and provide potential target genes for clinical diagnosis and targeted therapy.

\section{Introduction}

Head and neck cancer (HNC) is the sixth most common cancer worldwide (1). Annually, about 650,000 new cases and 350,000 deaths are reported worldwide, accounting for $6 \%$ of all cases $(1,2)$. High-risk regions for lip and oral cavity cancers include Melanesia, South-Central Asia, and Central and Eastern Europe (2). High-risk regions for laryngeal cancer include Southern and Eastern Europe and Western Asia (2). Indonesia, Singapore, and Malaysia, which are inhabited to a large extent by Malay and Chinese individuals, have the highest incidence of nasopharyngeal carcinoma (3). Mounting evidence suggests that genetic variations or abnormal expression of keratinocyte differentiation associated protein, heme oxygenase 1 (HMOX1), Rac family small GTPase 1 (Rac1), and desmocollin 1 (DSC1) may be associated with the carcinogenesis and progression of head and neck tumors. Studies have also found that HMOX1 and keratin-associated proteins are associated with human papillomavirus (HPV)-related HNC $(4,5)$. Inhibition of Racl activity may help to overcome primary or secondary chemo-radio-resistance in HNC (6). Occurrence and clinical prognosis of HNC are associated with overexpression of DSC1 (7). Early diagnosis and early treatment are keys to successful treatment of HNC, but no tumor markers with high specificity and sensitivity, or an effective therapeutic target, have been identified. Therefore, the survival rate and quality of life of patients with HNC is poor. As such, it is necessary to characterize the molecular mechanisms involved in the carcinogenesis of head and neck tumors. Better understanding of these mechanisms will allow for improved guidelines for diagnosis and treatment of head and neck tumors.

To explore the genetic alterations in head and neck tumors, identify new high-specificity and high-sensitivity tumor markers, and identify potentially effective therapeutic targets, in silico methods were used to study HNC. In the present study, GSE58911 was downloaded and analyzed from the Gene Expression Omnibus (GEO) database to obtain differentially expressed genes (DEGs) between HNC tissues 
and non-cancerous tissues. Subsequently, Kyoto Encyclopedia of Genes and Genomes (KEGG) pathway analysis, Gene Ontology (GO) enrichment analysis, and protein-protein interaction (PPI) network analysis was performed to characterize the molecular mechanisms underlying carcinogenesis and progression of HNC. A total of 648 differentially expressed genes and 26 hub genes were identified, which may be potential targets for clinical diagnosis and therapy of HNC.

\section{Materials and methods}

Microarray data. Gene Expression Omnibus (http://www. ncbi.nlm.nih.gov/geo) is a public functional genomics data repository of high throughout gene expression data, chips, and microarrays $(8,9)$. Platform (GPL) and Series (GSE) constitute the data from GEO. The gene expression dataset (GSE58911) (10) was downloaded from GEO (Affymetrix GPL6244, Affymetrix Human Gene 1.0 ST Array) and contains $15 \mathrm{HNC}$ samples and 15 normal tissues distant to the HNC sample.

Identification of DEGs. DEGs between cancerous and non-cancerous tissues were screened using GEO2R (http://www.ncbi.nlm.nih.gov/geo/geo2r). To identify genes that are differentially expressed across experimental conditions, GEO2R, an interactive web tool, allows users to compare $>2$ groups of samples in a GEO Series. Results are presented as a table of genes ordered by significance. Log fold-change $(\mathrm{FC}) \geq 1$ or $\leq-1$ and adjusted $\mathrm{P}$-value $<0.05$ were considered to be statistically different.

KEGG and GO enrichment analysis of DEGs. A comprehensive set of functional annotation tools were provided by the Database for Annotation, Visualization, and Integrated Discovery (DAVID; http://david.ncifcrf.gov) (version 6.8). DAVID is an online biological information database for investigators to understand biological significance underlying a large number of genes (11). KEGG (http://www.kegg.jp), an integrated database resource, is used for the biological interpretation of genome sequences and other high-throughput data (12). The GO (www.geneontology.org) project is a major bioinformatics tool and represents the most comprehensive resource currently available for computable knowledge regarding the functions of genes and gene products (13). Enrichment analysis from GO and KEGG pathways for differentially expressed genes was obtained using DAVID. $\mathrm{P}<0.05$ was considered to indicate a statistically significant difference.

PPI network construction and analysis. A PPI network of DEGs was constructed using the Search Tool for the Retrieval of Interacting Genes (STRING) online database (version 10.5; http://string-db.org) (14). Through the STRING database, DEGs with a combined score $\geq 0.4$ were chosen to construct a PPI network which could be visualized using Cytoscape software (version 3.4.0; www.cytoscape.org) (15). The functional modules of the PPI network were then identified using the Molecular Complex Detection (MCODE) (version 1.4.2) plug-in of Cytoscape (16). The criteria for selection were as follows: Max depth, 100; degree cut-off, 2; k-score, 2 and node score cut-off, 0.2 .
Hub gene selection and analysis. Hub genes were selected using Cytoscape software. A network of hub genes and their co-expressed genes was analyzed using the cBioPortal for Cancer Genomics (http://www.cbioportal.org) (17,18), which allows for visualization, analysis, and download of large-scale cancer genomics data sets. Hierarchical clusters of hub genes were constructed using the next generation University of California Santa Cruz (UCSC) Cancer Browser: UCSC Xena (http://xena.ucsc.edu) (19). The sample source 'The Cancer Genome Atlas Head-Neck Squamous Cell Carcinoma (HNSC)' was selected for these 26 hub genetic analyses and 604 samples were selected for analysis. The overall survival and disease-free survival rate analyses of hub genes was performed by constructing Kaplan-Meier curves using the cBioPortal online platform (statistical analysis performed is a log-rank test). Furthermore, the relationship between expression patterns, tumor grades, and HPV infection status was analyzed using Oncomine (https://www.oncomine. org) (20-29).

\section{Results}

Identification and PPI network construction of DEGs in $H N C$. After the standardization of the microarray results, 648 differentially expressed genes were identified between HNC tissues and normal tissues. The results from the GSE58911 dataset are represented as a volcano plot (Fig. 1A). The PPI network of DEGs was constructed (Fig. 1B). There were 554 nodes and 1574 edges in the PPI network, and the average node score was 5.68 (Fig. 1B).

GO and KEGG pathway enrichment analyses of DEGs. To analyze the biological classification of DEGs, GO and KEGG pathway enrichment analyses were performed using DAVID (Table I). The results of GO analysis showed that changes in biological processes of DEGs were mainly 'enriched in muscle system process', 'extracellular matrix organization', 'muscle contraction', 'extracellular structure organization', and 'muscle filament sliding'. Molecular function DEGs included 'actin binding', 'structural constituent of muscle', 'cytoskeletal protein binding', 'structural molecule activity' and 'actinin binding'. Cell component DEGs included 'extracellular region part', 'contractile fiber', 'extracellular region', 'sarcomere', and 'myofibril'. KEGG pathway analysis showed that the DEGs were mainly enriched in 'extracellular matrix (ECM)-receptor interaction', 'focal adhesion', 'amoebiasis', 'drug metabolism-cytochrome P450', 'chemical carcinogenesis', 'dilated cardiomyopathy', 'small cell lung cancer', 'hypertrophic cardiomyopathy', and 'retinol metabolism'.

Hub gene selection and analysis. Using the MCODE plug-in of Cytoscape, 26 genes were identified as hub genes. The results of GO and KEGG pathway analyses indicated that the hub genes were mainly enriched in 'extracellular matrix organization', 'collagen catabolic process', 'extracellular structure organization', 'multicellular organism catabolic process', 'collagen metabolic process', 'serine-type endopeptidase activity', 'extracellular matrix', 'proteinaceous extracellular matrix', 'extracellular space', 'extracellular region part', 'extracellular region', and 'complement and coagulation cascades' 
A
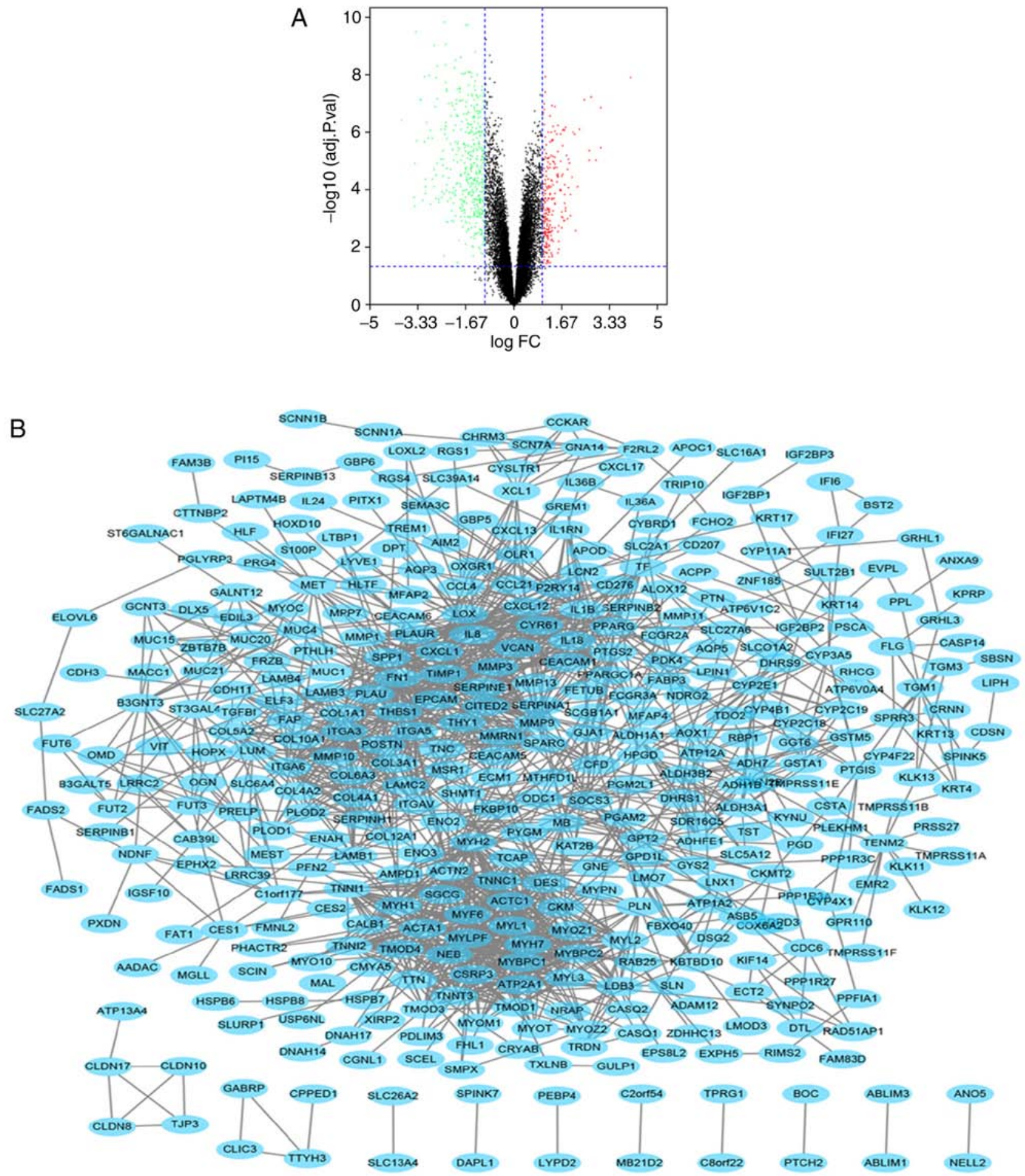

Figure 1. Volcano plot and PPI network of DEGs. (A) DEGs were selected with a fold change $\geq 2$ or $\leq-2$ and adjusted P-value $<0.05$ in the GSE58911 dataset. The green dot indicates that the expression of the gene in the tumor was $\leq$ one-half of that in the normal tissues, whereas the red dot indicates that the expression of the gene in the tumor was $\geq$ twice that of the normal tissues $(\mathrm{P}<0.05)$. The black dots represent genes which were not considered differentially expressed. (B) The PPI network of DEGs was constructed using Cytoscape. PPI, protein-protein interaction. DEGs, differentially expressed genes; FC, fold-change.

(Table II). The abbreviations, official full names, and synonyms for these hub genes are shown in Table III. A network of the hub genes and their co-expressed genes was analyzed using cBioPortal for Cancer Genomics (Fig. 2A). Hierarchical clustering revealed that the expression of hub genes could differentiate the HNC samples from normal samples (Fig. 2B). From figure $2 \mathrm{~B}$, it can be seen that 22 of the 26 hub genes were highly expressed in head and neck tumors compared with normal tissues, whereas expression of four genes (MMRN1/ECM1/EXCL12/CFD) was relatively high in the normal tissues. Furthermore, hierarchical clustering showed that HPV infection status determined by fluorescent in situ hybridization (FISH) testing (Fig. 2C) and P16 testing (Fig. 2D) was negatively associated with expression of the gene, although the mechanisms remains unknown. Overall survival rate analysis of the hub genes was performed using Kaplan-Meier 
Table I. GO and KEGG pathway enrichment analysis of DEGs in head and neck cancer.

\begin{tabular}{|c|c|c|c|}
\hline ID & Description & Count in gene set & P-value \\
\hline GO:0003012 & Muscle system process & 54 & $1.63 \times 10^{-19}$ \\
\hline GO:0030198 & Extracellular matrix organization & 49 & $1.86 \times 10^{-19}$ \\
\hline GO:0043062 & Extracellular structure organization & 49 & $2.12 \times 10^{-19}$ \\
\hline GO:0006936 & Muscle contraction & 48 & $7.41 \times 10^{-19}$ \\
\hline GO:0030049 & Muscle filament sliding & 19 & $7.21 \times 10^{-18}$ \\
\hline GO:0003779 & Actin binding & 42 & $1.61 \times 10^{-11}$ \\
\hline GO:0008307 & Structural constituent of muscle & 15 & $1.63 \times 10^{-11}$ \\
\hline GO:0008092 & Cytoskeletal protein binding & 63 & $2.75 \times 10^{-10}$ \\
\hline GO:0005198 & Structural molecule activity & 58 & $1.91 \times 10^{-09}$ \\
\hline GO:0042805 & Actinin binding & 9 & $2.04 \times 10^{-06}$ \\
\hline GO:0044421 & Extracellular region part & 233 & $1.75 \times 10^{-23}$ \\
\hline GO:0005576 & Extracellular region & 258 & $4.88 \times 10^{-22}$ \\
\hline GO:0043292 & Contractile fiber & 45 & $9.81 \times 10^{-22}$ \\
\hline GO:0030017 & Sarcomere & 41 & $3.45 \times 10^{-21}$ \\
\hline GO:0030016 & Myofibril & 43 & $6.08 \times 10^{-21}$ \\
\hline hsa04512 & ECM-receptor interaction & 18 & $8.56 \times 10^{-10}$ \\
\hline hsa05146 & Amoebiasis & 17 & $1.28 \times 10^{-07}$ \\
\hline hsa04510 & Focal adhesion & 22 & $1.30 \times 10^{-06}$ \\
\hline hsa00982 & Drug metabolism-cytochrome P450 & 12 & $6.32 \times 10^{-06}$ \\
\hline hsa05204 & Chemical carcinogenesis & 12 & $3.11 \times 10^{-05}$ \\
\hline hsa05414 & Dilated cardiomyopathy & 12 & $4.95 \times 10^{-05}$ \\
\hline hsa05222 & Small cell lung cancer & 12 & $5.54 \times 10^{-05}$ \\
\hline hsa05410 & Hypertrophic cardiomyopathy & 11 & $1.31 \times 10^{-04}$ \\
\hline hsa00830 & Retinol metabolism & 9 & $8.20 \times 10^{-04}$ \\
\hline
\end{tabular}

GO, Gene Ontology; KEGG, Kyoto Encyclopedia of Genes and Genomes; DEGs, differentially expressed genes.

Table II. GO and KEGG pathway enrichment analysis of DEGs in the hub genes.

\begin{tabular}{llrr}
\hline ID & \multicolumn{1}{c}{ Description } & Count in gene set & FDR \\
\hline GO:0030198 & Extracellular matrix organization & 14 & $1.89 \times 10^{-13}$ \\
GO:0043062 & Extracellular structure organization & 14 & $1.89 \times 10^{-13}$ \\
GO:0030574 & Collagen catabolic process & 9 & $4.00 \times 10^{-11}$ \\
GO:0044243 & Multicellular organism catabolic process & 9 & $9.48 \times 10^{-11}$ \\
GO:0032963 & Collagen metabolic process & 9 & $3.14 \times 10^{-09}$ \\
GO:0004252 & Serine-type endopeptidase activity & 6 & 0.041480238 \\
GO:0031012 & Extracellular matrix & 16 & $2.44 \times 10^{-13}$ \\
GO:0005578 & Proteinaceous extracellular matrix & 17 & $2.30 \times 10^{-12}$ \\
GO:0005615 & Extracellular space & 23 & $3.11 \times 10^{-08}$ \\
GO:0044421 & Extracellular region part & 24 & $3.86 \times 10^{-08}$ \\
GO:0005576 & Extracellular region & 5 & $6.42 \times 10^{-08}$ \\
hsa04610 & Complement and coagulation cascades & 0.039461461
\end{tabular}

GO, Gene Ontology; KEGG, Kyoto Encyclopedia of Genes and Genomes; DEGs, differentially expressed genes; FDR, false discovery rate.

curves in the cBioPortal online platform. Patients with HNC and high expression of interleukin (IL)8, IL1B and serpin family A member 1 (SERPINA1) had worse overall survival and worse disease-free survival (Fig. 3A and B). Oncomine analysis of cancer vs. normal tissues indicated that IL8, IL1B, and SERPINA1 were over-expressed in HNC in the different datasets (Fig. 4A, B and C). Higher mRNA expression levels of IL8 was associated with tumor grade $(\mathrm{P}=0.001)$. However, 
Table III. Abbreviations, official full names and synonyms for the 26 hub genes.

\begin{tabular}{|c|c|c|c|}
\hline Number & Gene symbol & Official full name & Also known as \\
\hline 1 & TNC & Tenascin $\mathrm{C}$ & $\begin{array}{l}\text { GP; JI; TN; HXB; GMEM; TN-C; DFNA56; } \\
\text { 150-225 }\end{array}$ \\
\hline 2 & PLOD2 & Procollagen-lysine,2-oxoglutarate 5-dioxygenase 2 & LH2; TLH; BRKS2 \\
\hline 3 & COL3A1 & Collagen type III alpha 1 chain & EDS4A; EDSVASC \\
\hline 4 & IL1B & Interleukin 1 beta & IL-1; IL1F2; IL1-BETA \\
\hline 5 & COL12A1 & Collagen type XII alpha 1 chain & $\begin{array}{l}\text { UCMD2; BTHLM2; EDSMYP; COL12A1L; } \\
\text { BA209D8.1; DJ234P15.1 }\end{array}$ \\
\hline 6 & COL5A2 & Collagen type $\mathrm{V}$ alpha 2 chain & EDSC; EDSCL2 \\
\hline 7 & MMRN1 & Multimerin 1 & ECM; MMRN; GPIa; EMILIN4 \\
\hline 8 & IL8 & $\mathrm{C}-\mathrm{X}-\mathrm{C}$ motif chemokine ligand 8 & $\begin{array}{l}\text { NAF; GCP1; LECT; LUCT; NAP1; GCP-1; } \\
\text { LYNAP; MDNCF; MONAP; NAP-1 }\end{array}$ \\
\hline 9 & PLAU & Plasminogen activator, urokinase & ATF; QPD; UPA; URK; u-PA; BDPLT5 \\
\hline 10 & PLAUR & Plasminogen activator, urokinase receptor & CD87; UPAR; URKR; U-PAR \\
\hline 11 & ECM1 & Extracellular matrix protein 1 & URBWD \\
\hline 12 & SERPINE1 & Serpin family E member 1 & PAI; PAI1; PAI-1; PLANH1 \\
\hline 13 & MMP9 & Matrix metallopeptidase 9 & GELB; CLG4B; MMP-9; MANDP2 \\
\hline 14 & TIMP1 & TIMP metallopeptidase inhibitor 1 & EPA; EPO; HCI; CLGI; TIMP; TIMP-1 \\
\hline 15 & COL10A1 & Collagen type $X$ alpha 1 chain & \\
\hline 16 & CXCL12 & $\mathrm{C}-\mathrm{X}-\mathrm{C}$ motif chemokine ligand 12 & IRH; PBSF; SDF1; TLSF; TPAR1; SCYB12 \\
\hline 17 & COL6A3 & Collagen type VI alpha 3 chain & DYT27; UCMD1; BTHLM1 \\
\hline 18 & MMP1 & Matrix metallopeptidase 1 & CLG; CLGN \\
\hline 19 & PTGS2 & Prostaglandin-endoperoxide synthase 2 & $\begin{array}{l}\text { COX2; COX-2; PHS-2; PGG/HS; PGHS-2; } \\
\text { hCox-2; GRIPGHS }\end{array}$ \\
\hline 20 & PLOD1 & Procollagen-lysine,2-oxoglutarate 5-dioxygenase 1 & LH; LH1; LLH; EDS6; PLOD; EDSKCL1 \\
\hline 21 & MMP13 & Matrix metallopeptidase 13 & CLG3; MDST; MANDP1; MMP-13 \\
\hline 22 & SPP1 & Secreted phosphoprotein $1 \mathrm{pr}$ & OPN; BNSP; BSPI; ETA-1 \\
\hline 23 & SERPINA1 & Serpin family A member 1 & $\begin{array}{l}\text { PI; A1A; AAT; PI1; A1AT; nNIF; PRO2275; } \\
\text { alpha1AT }\end{array}$ \\
\hline 24 & CFD & Complement factor D & DF; ADN; PFD; ADIPSIN \\
\hline 25 & MMP3 & Matrix metallopeptidase 3 & $\begin{array}{l}\text { SL-1; STMY; STR1; CHDS6; MMP-3; } \\
\text { STMY1 }\end{array}$ \\
\hline 26 & SPARC & Secreted protein acidic and cysteine rich & OI17; BM-40 \\
\hline
\end{tabular}

the mRNA expression levels of IL1B and SERPINA1 were not associated with tumor grade $(\mathrm{P}>0.05)$. Higher mRNA expression levels of IL8 $\left(\mathrm{P}=6.30 \times 10^{-9}\right)$ and IL1B $\left(\mathrm{P}=3.48 \times 10^{-6}\right)$ were associated with HPV infection status. The mRNA expression levels of SERPINA1 however, were not associated with HPV infection status (Fig. 5A-F).

\section{Discussion}

$\mathrm{HNC}$ is the sixth most common cancer worldwide and is associated with severe disease- and treatment-related morbidity, with a 5-year survival rate of $<60 \%(1,2)$. The survival rate has not improved across more than two decades due to lack of early detection $(30,31)$. There are two primary causes of HNC: Tobacco and alcohol use, and human papillomavirus infection (32). Previous studies have shown that HPV infection plays a role in the pathogenesis of head and neck tumors (33-35). The oncomine analysis of cancer vs. normal tissue for IL8, IL1B and SERPINA1 demonstrated that the expression was compared with the normal tissues (Fig. 4). mRNA expressions of IL8, IL1B and SERPINA1 were higher in the HPV-negative group compared with that in the HPV-positive group (Fig. 5D-F). These seemingly contradictory results are understandable. There are many studies suggesting that HPV-positive head and neck tumors were associated with improved disease-free and overall survival $(32,36)$. According to the present study, IL8, IL1B and SERPINA1 are highly expressed in the HNC, and the results in Fig. 3 indicate that the overall survival rate and disease-free survival rate of patients with high expression of these 3 genes are worse. Therefore, it is understandable that IL8, IL1B and SERPINA1 have higher expressions in HPV-negative tumor patients. However, the underlying molecular mechanisms of HNC remain unclear. Abnormal expression of transglutaminase 3, regenerating islet-derived protein 3 , keratin 8 , and phosphatase and tensin homolog is associated with HNC (37-40). In 
A

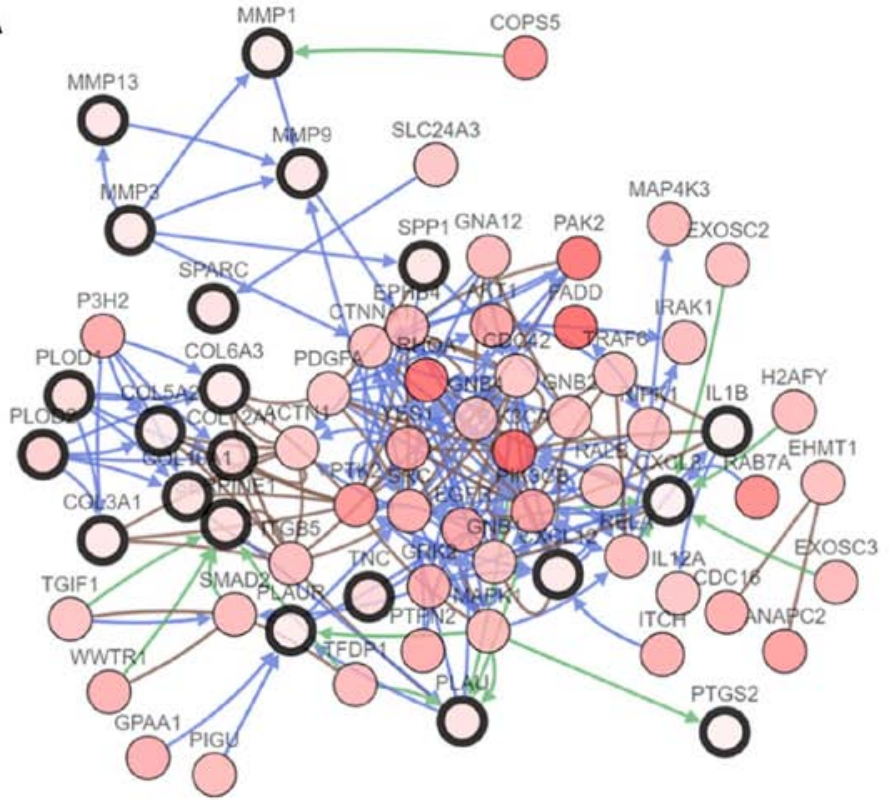

B
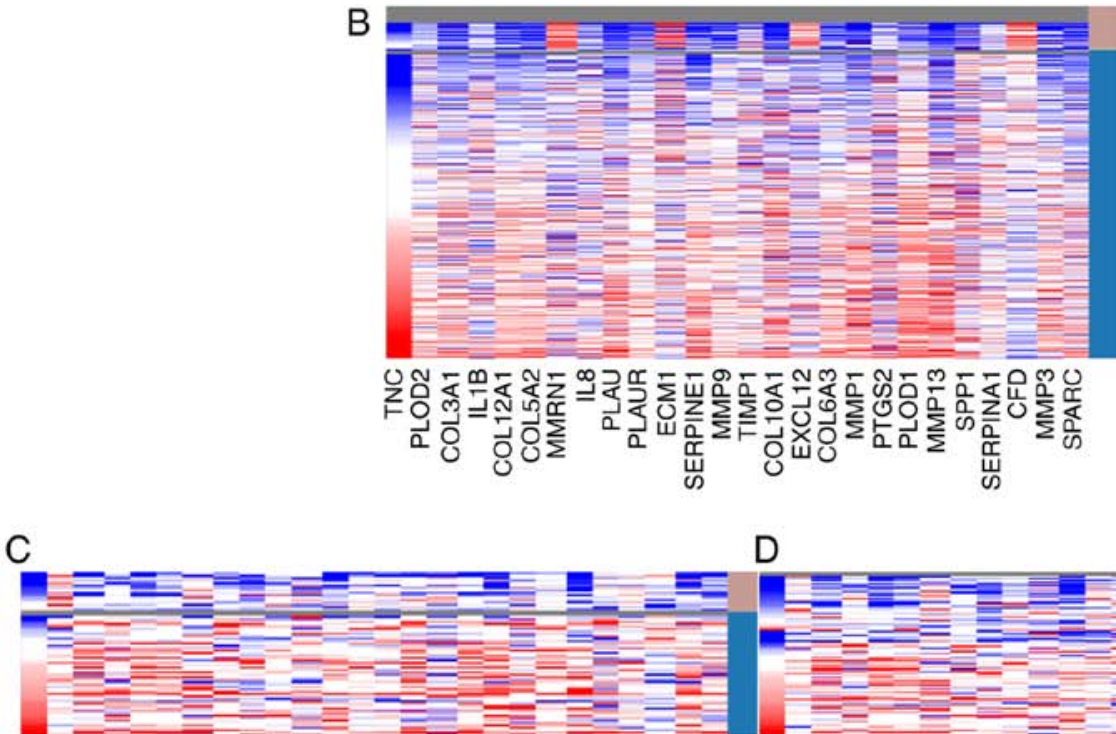

D
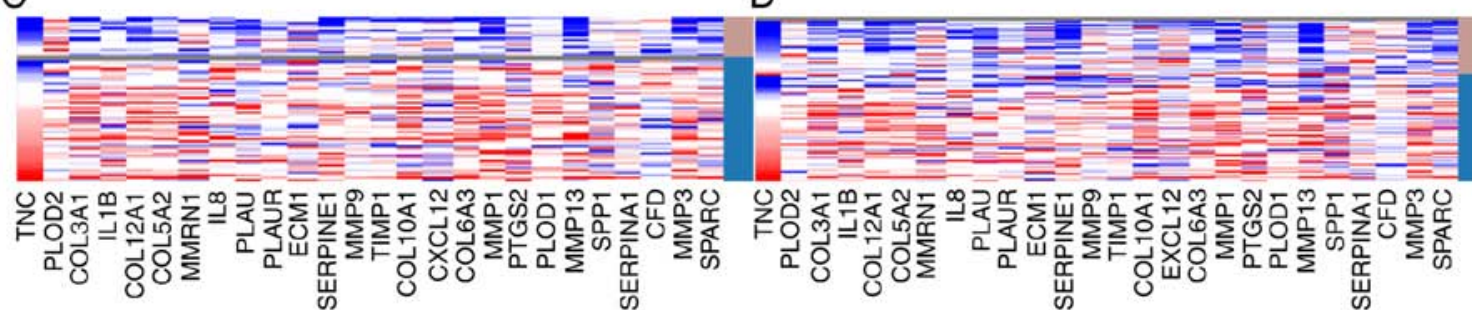

Figure 2. Analysis of hub genes and their co-expressed genes, and hierarchical clustering of hub genes. (A) Hub genes and their co-expressed genes were analyzed using cBioPortal. Nodes with bold black outlines represent hub genes. Nodes with thin black outlines represent co-expressed genes. The color in the circle represents the total alteration of the gene in the genomic profiles, including the up and downregulation. The intensity of the color depicts a larger alteration. The blue arrow represents a 'controls-state-change-of' interaction; whereas the green arrow represents a 'controls-expression-of' interaction. (B, C and D) Hierarchical clustering of hub genes was constructed using University of California Santa Cruz. (B) The samples grouped by the brown bar are non-cancerous samples and the samples grouped by the blue bar are HNC samples. The samples grouped by the brown bar are HPV-positive samples and the samples grouped by the blue bar are HPV-negative samples that were tested using. (C) Fluorescent in situ hybridization and (D) P16. Red indicates the upregulation of genes and blue indicates the downregulation of genes.

addition, mutations within tumor protein $\mathrm{p} 53$, notch receptor 1, phosphatidylinositol-4,5-bisphosphate 3-kinase catalytic subunit $\alpha, \mathrm{X}$-ray repair cross complementing 1 and epidermal growth factor receptor have been reported to be involved in HNC (41-44). Patients with HNC that do not detect the cancer early have no effective treatments available except receiving palliative care, which leads to poor prognosis and quality of life, and a high rate of mortality (30). Therefore, there is an urgent need to identify potential target biomarkers that can be used to efficiently diagnose and treat HNC. Bioinformatics technology allows us to explore genetic differences between HNC and normal tissues, which can be used to identify potential biomarkers. Then, effective genes can be selected through screening and experimental validation for early diagnosis, clinical prognosis, and treatment of HNC.

In the present study, the dataset GSE58911 was analyzed to obtain differentially expressed genes between HNC and non-cancerous tissues. A total of 648 DEGs were identified. 
A
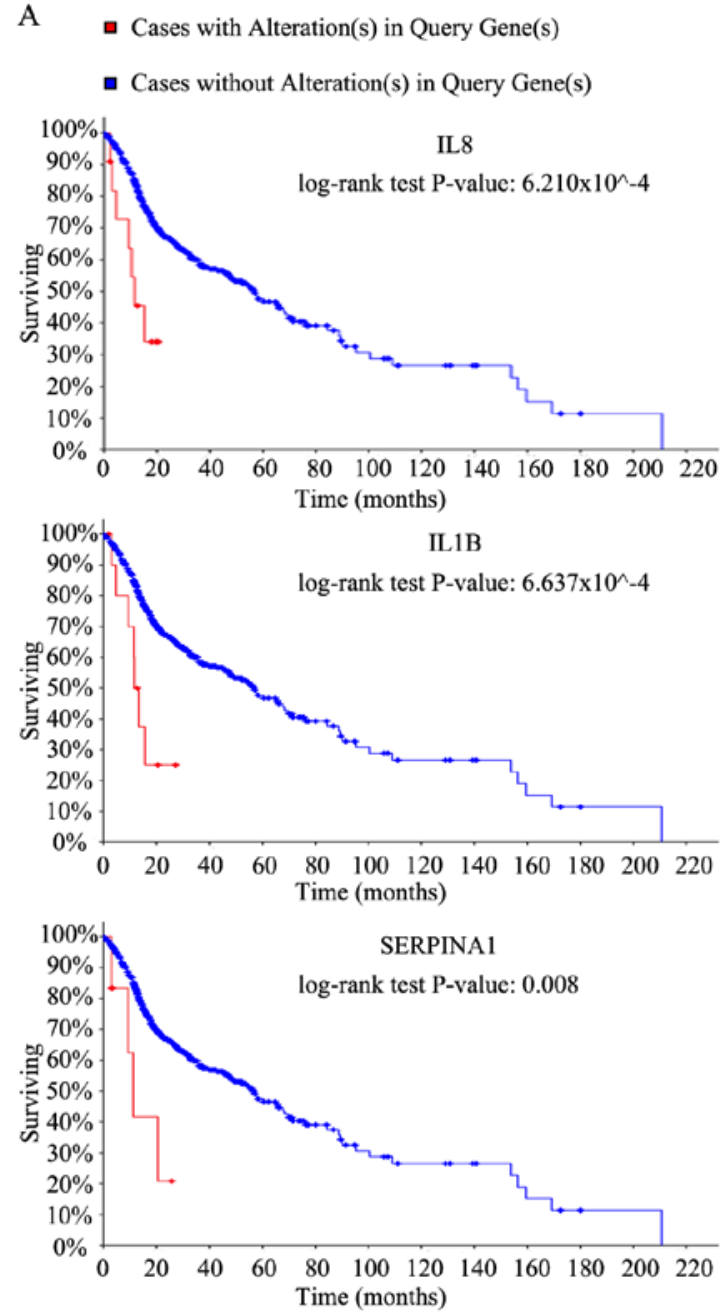

- Cases with Alteration(s) in Query Gene(s)

- Cases without Alteration(s) in Query Gene(s)
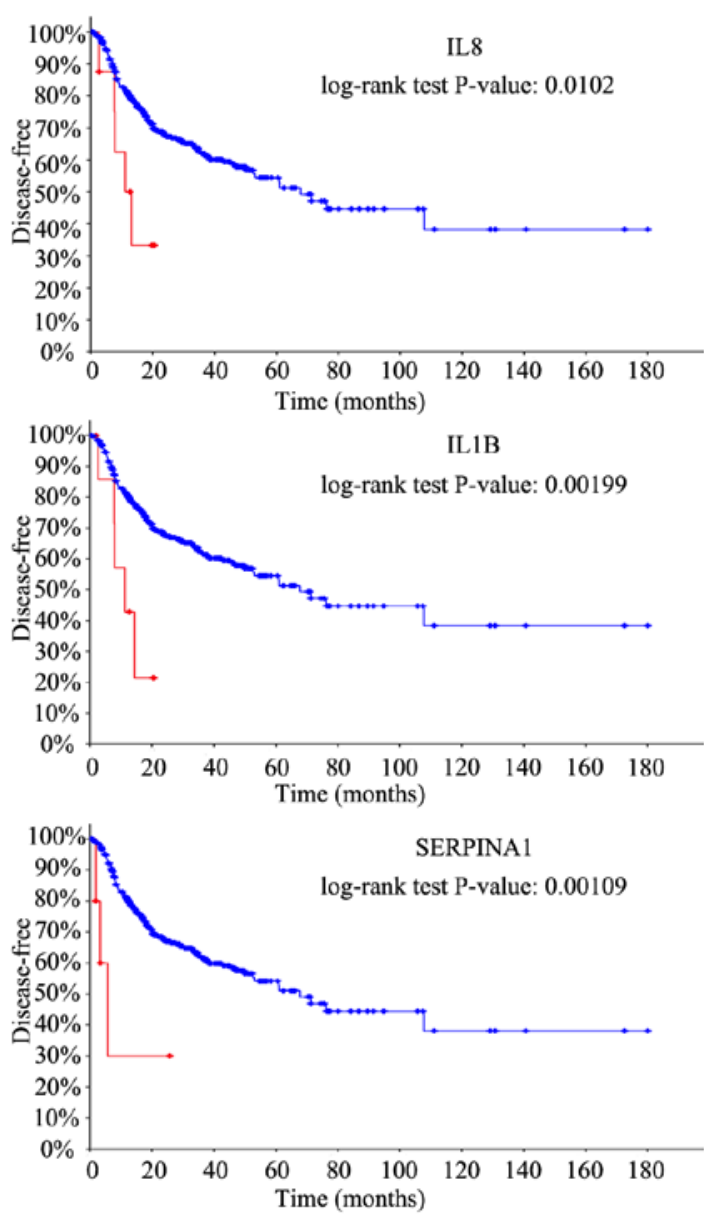

Figure 3. (A) Overall survival and (B) disease-free survival analyses based on the expression of IL8, IL1B, and SERPINA1 were performed using the cBioPortal online platform. P<0.05 was considered statistically significant. IL, interleukin; SERPINA1, serpin family A member 1.

GO and KEGG enrichment analyses were performed to explore interactions among these genes and they were mainly enriched in 'extracellular matrix organization', 'actin binding', 'extracellular region', 'ECM-receptor interaction', 'drug metabolism-cytochrome $\mathrm{P} 450$ ', and 'chemical carcinogenesis'. Previous studies reported that 'extracellular matrix organization', 'actin binding', and 'ECM-receptor interaction' play important roles in the carcinogenesis, progression, and metastasis of tumors (45-48). In addition, previous data indicated that focal adhesion, drug metabolism-cytochrome P450, and chemical carcinogenesis are involved in radio- and chemotherapy (49-52). Thus, the findings from the present study are consistent with results from previous studies. GO enrichment analysis indicated that changes in hub genes were mainly enriched in 'extracellular matrix organization', 'collagen catabolic process', 'serine-type endopeptidase activity', 'extracellular matrix', and 'proteinaceous extracellular matrix', while changes according to KEGG pathway analysis were mainly enriched in 'complement and coagulation cascades'.

A total of 26 DEGs were selected as hub genes, among which survival rates and disease-free survival rates between patients with head and neck tumors and patients without tumors were significantly associated with the expression of IL8, IL1B, and
SERPINA1. IL8 is a chemotactic factor that attracts neutrophils, basophils, and T-cells, but not monocytes (53) and can be released by several cell types in response to inflammatory stimuli (53). Higher IL8 expression was observed in HNSCC tissue $(54,55)$. Furthermore, IL8 stimulated the proliferation of HNSC cells $(55,56)$. In addition, a previous study showed that the tumor microenvironment plays a vital role in HNC initiation, progression, and metastasis (57). Tumor-associated macrophages can promote cancer initiation and progression by releasing cytokines and may facilitate papillary thyroid carcinoma (PTC) cell metastasis through IL8 and its paracrine interaction with C-X-C chemokine receptor CXCR1 and CXCR2 (58). Thus, IL8 may be a potential therapeutic target.

IL1B is a potent pro-inflammatory cytokine. Initially discovered as the major endogenous pyrogen, IL1B induces prostaglandin synthesis, neutrophil influx and activation, cytokine production, $\mathrm{T}$ cell and $\mathrm{B}$ cell activation, antibody production, collagen production, and fibroblast proliferation (59). A recent study of IL1B has shown that it plays a major role in tumor chemotherapy resistance. Anakinra can block the IL-1 pathway and overcome erlotinib resistance in HNSCC, which may represent a novel strategy to overcome EGFR inhibitor resistance, allowing for more effective treatment of patients with 
A

\begin{tabular}{|c|c|c|c|c|c|c|c|c|c|c|c|c|}
\hline Median Rank & P-value & Gene & & & & & & & & & & \\
\hline \multirow[t]{2}{*}{1483.0} & $3.21 \times 10^{\wedge}-4$ & IL8 & & & & & & & & & & \\
\hline & & & 1 & 2 & 3 & 4 & 5 & 6 & 7 & 8 & 9 & 10 \\
\hline
\end{tabular}

1.P-value $=1.0 \times 10^{\wedge}-3$ fold change $=23.677 \quad 2 . P$-value $=3.21 \times 10^{\wedge}-4$ fold change $=3.495$

4.P-value $=1.4 \times 10^{\wedge}-2$ fold change $=2.268 \quad 5 . P$-value $=2.76 \times 10^{\wedge}-20$ fold change $=20.342$

7.P-value $=3.5 \times 10^{\wedge}-2$ fold change $=8.581 \quad 8 . P$-value $=5.0 \times 10^{\wedge}-3$ fold change $=7.141$

10. $P$-value $=3.5 \times 10^{\wedge}-2$ fold change $=3.403 \quad 11 . P$-value $=7.11 \times 10^{\wedge}-11$ fold change $=10.158$

B

\begin{tabular}{|c|c|c|c|c|c|c|c|}
\hline Median Rank & P-value & Gene & & & & & \\
\hline \multirow[t]{2}{*}{552.0} & $1.77 \times 10^{\wedge}-8$ & IL1B & & & & & \\
\hline & & & 1 & 2 & 3 & 4 & 5 \\
\hline
\end{tabular}

1.P-value $=2.0 \times 10^{\wedge}-3$ fold change $=4.908 \quad 2 . P$-value $=1.95 \times 10^{\wedge}-6$ fold change $=2.409$ 4.P-value $=4.52 \times 10^{\wedge}-10$ fold change $=3.2895 . P$-value $=2.67 \times 10^{\wedge}-6$ fold change $=2.876$

C

Median Rank P-value Gene

$128.0 \quad 1.22 \times 10^{\wedge}-18$ SERPINA1

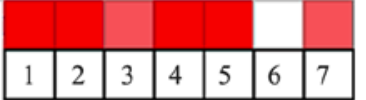

1.P-value $=1.36 \times 10^{\wedge}-13$ fold change $=7.6262 . P$-value $=6.18 \times 10^{\wedge}-7$ fold change $=2.969$ 4.P-value $=1.11 \times 10^{\wedge}-10$ fold change $=14.4445 . P$-value $=1.22 \times 10^{\wedge}-18$ fold change $=2.439$ 7.P-value $=1.0 \times 10^{\wedge}-3$ fold change $=6.739$

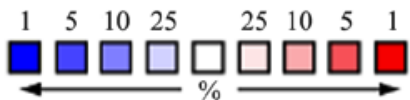

Figure 4. Oncomine analysis of cancer vs. normal tissue for IL8, IL1B and SERPINA1. Heat maps of IL8, IL1B, and SERPINA1 gene expression in clinical HNC samples vs. normal tissues. Red represents high expression and blue represents low expression and the color reflects the median rank, not the expression value. (A) 1. Head and neck squamous cell carcinoma vs. normal tissue (21). 2. Tongue squamous cell carcinoma vs. normal tissue (22). 3. Head and neck squamous cell carcinoma vs. normal tissue (23). 4. Thyroid gland papillary carcinoma vs. normal tissue (24). 5. Oral cavity squamous cell carcinoma vs. normal tissue (25). 6. Floor of the mouth carcinoma vs. normal tissue (26). 7. Oral cavity carcinoma vs. normal tissue (26). 8. Oropharyngeal carcinoma vs. normal tissue (26). 9. Tongue carcinoma vs. normal tissue (26). 10. Tonsillar carcinoma vs. normal tissue (26). 11. Tongue squamous cell carcinoma vs. normal tissue (27). (B) 1. Head and neck squamous cell carcinoma vs. normal tissue (21). 2. Tongue squamous cell carcinoma vs. normal tissue (22). 3. Head and neck squamous cell carcinoma vs. normal tissue (23). 4. Oral cavity squamous cell carcinoma vs. normal tissue (23). 5. Tongue squamous cell carcinoma vs. normal tissue (27). (C) 1. Head and neck squamous cell carcinoma vs. normal tissue (23). 2. Tall cell variant thyroid gland papillary carcinoma vs. normal tissue (28). 3. Thyroid gland papillary carcinoma vs. normal tissue (28). 4. Thyroid gland papillary carcinoma vs. normal tissue (24). 5. Oral cavity squamous cell carcinoma vs. normal tissue (25). 6. Oropharyngeal carcinoma vs. normal tissue (26). 7. Thyroid gland papillary carcinoma vs. normal tissue (29). IL, interleukin; SERPINA1, serpin family A member 1.

HNSCC (60). Furthermore, high expression of inflammatory cytokines (IL8, IL1B) and shorter progression-free survival are significantly associated. The expression level of inflammatory cytokines may help to identify which patients with recurrent and/or metastatic squamous cell carcinoma of the head and neck are likely to benefit from dacomitinib (61).

SERPINA1, an inhibitor of serine proteases, irreversibly inhibits trypsin, chymotrypsin, and plasminogen activator (62). Its primary target is elastase, but it also has a moderate affinity for plasmin and thrombin (62). A recent study showed a higher abundance of SERPINA1 candidate biomarkers in the saliva of patients with oral squamous cell carcinoma (OSCC), demonstrating that SERPINA1 is related to OSCC development (63). Moreover, SERPINA1 may be related to PTC by responding to steroid hormone stimuli and regulating the epithelial-to-mesenchymal transition (64). Based on these associations, SERPINA1 may be an effective mRNA marker of PTC (65). Oncomine analysis indicated that higher mRNA levels of IL8, IL1B, and SERPINA1 were associated with tumor grade and HPV infection status, indicating vital roles of IL8, IL1B, and SERPINA1 in the carcinogenesis or progression of HNC.
In addition to IL1B, 1L8 and SERPINA1, which were associated with the survival rate of patients with head and neck cancer, other relevant hub genes that were identified in the present study are discussed.

Tenascin C (TNC), a gene associated with tumor metastatic potential, was upregulated in the OSCC cell line LNMTca8113 (66). In addition, vascular density and higher tumor stage were associated with differences in immuno-expression of stromal TNC, demonstrating its role in the tumorigenesis of juvenile nasopharyngeal angiofibroma (67).

A previous study showed that microRNA-29a/b could regulate the expression of collagen type III alpha 1 chain to enhance migration and invasion ability of nasopharyngeal carcinoma cells (68). The markers, the combination of collagen type $\mathrm{V}$ alpha 1 chain (COL5A1) and hemoglobin subunit beta and COL5A1 itself can better predict the treatment response in patients with oral tongue squamous cell carcinoma (69).

Poor disease-free survival and increased progression or relapse risk were associated with high plasminogen activator, urokinase (PLAU) expression. Moreover, circulating PLAU 

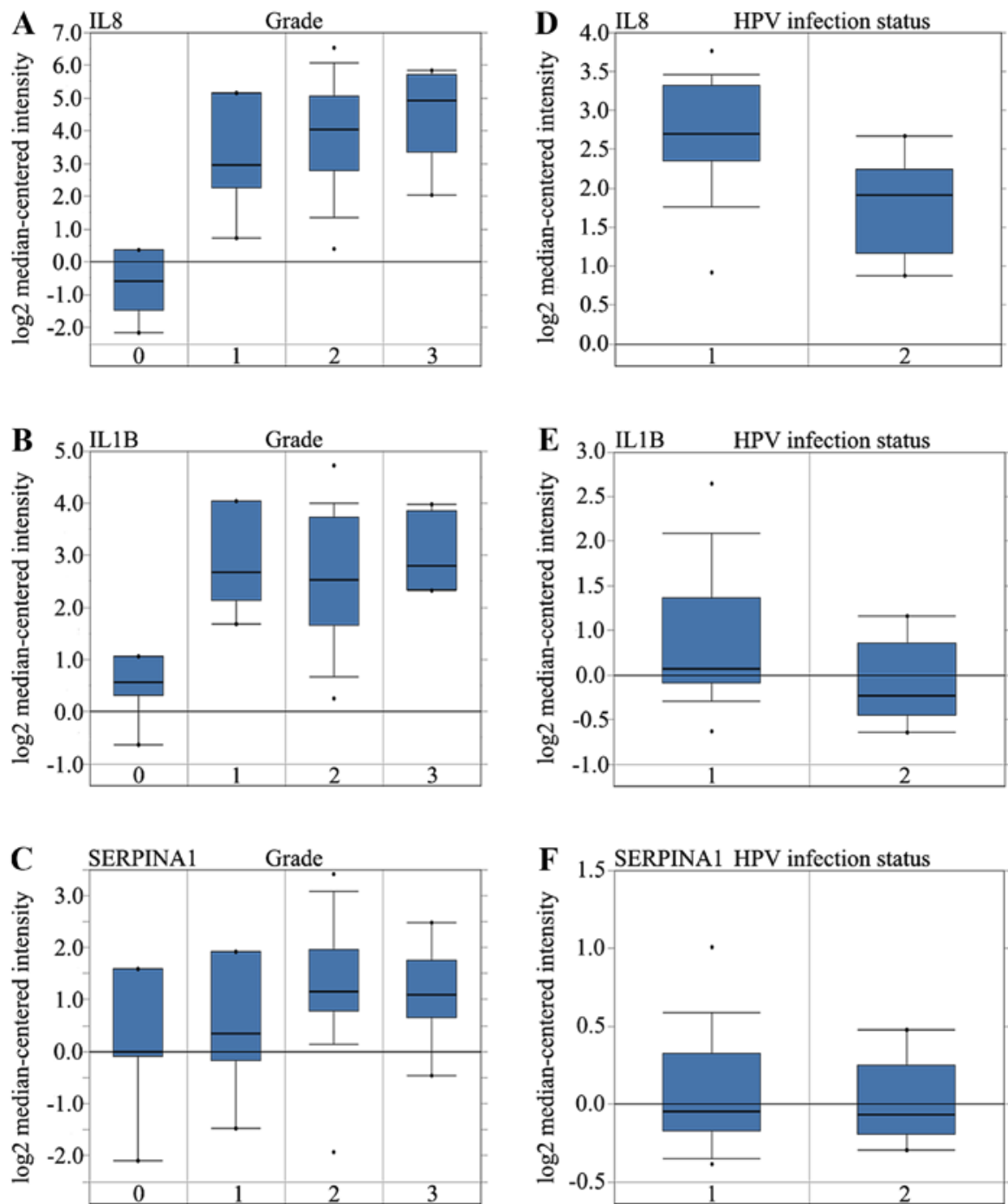

Figure 5. Association between the expression of IL8, IL1B, and SERPINA1, tumor grade, and HPV infection status in the different datasets. The datasets were obtained from the Oncomine database. The box plot represents the maximum, the 75 th percentile, the median, the $25^{\text {th }}$ percentile and the minimum value of data. (A-C) IL8, IL1B and SERPINA1 mRNA expression of HNC samples in the Cromer Head and Neck dataset. There were four patients in group 0 , representing with no grade; seven patients in group 1, representing Grade 1; nineteen patients in group 2, representing Grade 2; and eight patients in group 3, representing Grade 3. (D-F) IL8, IL1B, and SERPINA1 mRNA expression of HNC samples in the Slebos Head and Neck dataset. There were twenty-eight patients in group 1, representing HPV negative; and eight patients in group 2, representing HPV positive. IL, interleukin; SERPINA1, serpin family A member 1; HPV, human papillomavirus, HNC, head and neck cancer.

levels were significantly higher in the plasma of patients with HNSCC compared with that in healthy individuals (70).

Extracellular matrix protein 1 (ECM1) levels gradually increased from benign laryngeal lesions to precancerous to malignant lesions, and ECM1 was expressed at lower levels in laryngeal carcinomas without metastasis $(71,72)$. These results demonstrated that ECM1 facilitated development and metastasis of laryngeal carcinoma.

Overexpression of SERPINE1 promotes tumor migration and invasion and plays an important role in metastasis and poor prognosis of HNSCC (73). In addition, many researchers regard SERPINE1 as a prognostic marker based on its ability to stratify patients with HNSCC according to their recurrence risk (74).

Matrix metalloproteinases (MMPs) are a family of proteolytic enzymes that promote invasion and metastasis of various cancers due to their ability to degrade components of the extracellular matrix. MMP1, MMP3, MMP9, and MMP13 are predictors of poor clinical outcomes in patients with
HNC (75-78). Furthermore, specific tissue inhibitors of matrix metalloproteinases (TIMPs) can regulate MMP activity. In addition to $\mathrm{HNC}$, the majority of tumors are associated with alterations in MMPs and TIMPs. Imbalance between matrix metalloproteinases and their inhibitors contributes greatly to the progression and prognosis of HNC $(76,79)$.

Compared with normal oral mucosa, secreted phosphoprotein 1 was expressed at significantly higher levels in OSCC (80). According to a previous study, secreted protein acidic and cysteine rich had significant prognostic value, especially in the stroma surrounding OSCC (81). A literature search revealed that the interaction between $\mathrm{HNC}$ and the hub genes procollagen-lysine 2-oxoglutarate 5-dioxygenase (PLOD)-2, collagen type XII alpha 1 chain, multimerin 1 (MMRN1), plasminogen activator urokinase receptor, collagen type $\mathrm{X} \alpha 1$ chain, collagen type VI $\alpha 3$ chain, prostaglandin-endoperoxide synthase 2, PLOD1, and complement factor D (CFD) has not been widely reported. 
There were several limitations associated with the present study. First, only one series (GSE58911) downloaded and used from the GEO database. The number of tumor and normal samples in this series were both 15 . This sample size was insufficient. Second, genes were analyzed that may be related to the carcinogenesis or progression of head and neck tumors from the results of the bioinformatics analyses. The functions of these genes have not been verified in vitro and in vivo. In the present study, the expression levels of IL8 (C-X-C motif chemokine ligand 8), IL1B and SERPINA1 in tumor tissues and normal tissues of patients with head and neck tumors were not verified further. In addition, phenotypic function was also not verified in head and neck tumor cell lines. In future studies this will be investigated. Third, the number of hub genes (modes with bold black circles) in Fig. 2A is 21, and there are 5 hub genes (MMRN1, ECM1, TIMP metallopeptidase inhibitor 1, SERPINA1 and CFD) that do not appear in the network map. In particular, SERPINA1 is among one of the identified three genes following further analysis of the data. This could be due to the following reasons: i) These 5 genes may not be closely related to other genes, and have other roles and mechanisms in the occurrence and development of tumors, so they were excluded from the network map; ii) the 26 hub genes were obtained by analyzing 648 DEGs using the Cytoscape plug-in, MCODE. cBioPortal for Cancer Genomics was subsequently used to analyze these 26 hub genes to obtain a network map of hub genes and their co-expressed genes. The computer algorithms that each database performed for analysis may differ, and may also cause differences; iii) in addition, 3 hub genes (IL8, IL1B and SERPINA1) were selected for more in-depth analysis as cBioPortal for Cancer Genomics was used to analyze overall survival and disease-free survival rate for the 26 hub genes. Changes in the expression of IL8, IL1B and SERPINA1 in patients with head and neck tumors were associated with overall survival and disease-free survival rate, and were statistically significant; iv), a holistic analysis of 26 hub genes from 628 DEGs was performed in an attempt to obtain an inductive result (Fig. 2). In addition, 2 detection methods (FISH and P16 tests) of HPV infection were used to obtain more accurate results for further analysis. However, the profiles of IL8, IL1B and SERPINA1 in Fig. 2C and D are not consistent. This may be due to different detection methods or detection of HPV subtypes. This may require a more accurate method to detect the infection status of HPV for a more accurate analysis; and v), there are differences in the monitoring of overall survival and disease-free survival of patients between the gene alterations of IL8, IL1B and SERPINA1 (Fig. 3). Monitoring was performed for over 180 months (over 15 years) when there were no alteration(s) in these 3 genes while alterations in these genes was monitored for only 20 months. This may be due to the following reasons: i) These samples were obtained at different time points over a 10-year period and as such the samples may have degraded; ii) some patients cannot be contacted during follow-up or have died due to illness. An open source, free database was used therefore information pertaining to when the samples were collected and whether it was in different decades. In this regard, the lack of data beyond 20 months may be considered a limitation associated with the present study. However, using this database for analysis is reliable and credible. This database is used in many articles on bioinformatics analysis (82-84). These limitations will be addressed in future studies. Despite these limitations, research in the present study is important as it elucidated molecular mechanisms underlying development of $\mathrm{HNC}$, and also provides potential target genes for clinical diagnosis and targeted therapy. In addition, this provides direction for future studies of HNC.

In conclusion, the present study identified DEGs that may be involved in the carcinogenesis or progression of HNC. A total of 648 DEGs and 26 hub genes were identified and may have potential as target biomarkers for HNC. Further studies are needed to elucidate the biological functions of these genes in HNC.

\section{Acknowledgements}

Not applicable.

\section{Funding}

This study was supported by the National Natural Science Foundation of China (grant nos. 81372880 and 81670910) and the Guidance fund of the Renmin Hospital of Wuhan University (grant no. RMYD2018Z12).

\section{Availability of data and materials}

All data are fully available without restriction.

\section{Authors' contributions}

FC and ZT conceived and designed the study. FC, AZ, FL, SW, SC and ZT processed the data. FC wrote the paper. FC, AZ, FL, SW, SC, and ZT reviewed and edited the manuscript. All authors read and approved the manuscript.

\section{Ethics approval and consent participate}

Not applicable.

\section{Patient consent for publication}

Not applicable.

\section{Competing interests}

The authors declare that they have no competing interests.

\section{References}

1. Jemal A, Bray F, Center MM, Ferlay J, Ward E and Forman D: Global cancer statistics. CA Cancer J Clin 61: 69-90, 2011.

2. Torre LA, Bray F, Siegel RL, Ferlay J, Lortet-Tieulent J and Jemal A: Global cancer statistics, 2012. CA Cancer J Clin 65: 87-108, 2015.

3. Bray F, Ferlay J, Laversanne M, Brewster DH, Gombe MC, Kohler B, Piñeros M, Steliarova-Foucher E, Swaminathan R, Antoni S, et al: cancer incidence in five continents: Inclusion criteria, highlights from volume $\mathrm{X}$ and the global status of cancer registration. Int J Cancer 137: 2060-2071, 2015.

4. Thibodeau BJ, Geddes TJ, Fortier LE, Ahmed S, Pruetz BL, Wobb J, Chen P, Wilson GD and Akervall JA: Gene expression characterization of HPV positive head and neck cancer to predict response to chemoradiation. Head Neck Pathol 9: 345-353, 2015.

5. Min SK, Lee SK, Park JS, Lee J, Paeng JY, Lee SI, Lee HJ, Kim Y, Pae HO, Lee SK and Kim EC: Endoplasmic reticulum stress is involved in hydrogen peroxide induced apoptosis in immortalized and malignant human oral keratinocytes. J Oral Pathol Med 37: 490-498, 2008. 
6. Skvortsov S, Dudás J, Eichberger P, Witsch-Baumgartner M, Loeffler-Ragg J, Pritz C, Schartinger VH, Maier H, Hall J, Debbage $\mathrm{P}$, et al: Rac1 as a potential therapeutic target for chemo-radioresistant head and neck squamous cell carcinomas (HNSCC). Br J Cancer 110: 2677-2687, 2014.

7. Wang Y, Chen C, Wang X, Jin F, Liu Y, Liu H, Li T and Fu J: Lower DSCl expression is related to the poor differentiation and prognosis of head and neck squamous cell carcinoma (HNSCC). J Cancer Res Clin Oncol 142: 2461-2468, 2016.

8. Edgar R, Domrachev M and Lash AE: Gene expression omnibus: NCBI gene expression and hybridization array data repository. Nucleic Acids Res 30: 207-210, 2002

9. Barrett T, Wilhite SE, Ledoux P, Evangelista C, Kim IF, Tomashevsky M, Marshall KA, Phillippy KH, Sherman PM, Holko M, et al: NCBI GEO: Archive for functional genomics data sets-update. Nucleic Acids Res 41 (Database Issue): D991-D995, 2013.

10. Lobert S, Graichen ME, Hamilton RD, Pitman KT, Garrett MR, Hicks C and Koganti T: Prognostic biomarkers for HNSCC using quantitative real-time PCR and microarray analysis: $\beta$-tubulin isotypes and the p53 interactome. Cytoskeleton (Hoboken) 71: 628-637, 2014.

11. Huang DW, Sherman BT, Tan Q, Collins JR, Alvord WG, Roayaei J, Stephens R, Baseler MW, Lane HC and Lempicki RA: The DAVID gene functional classification tool: A novel biological module-centric algorithm to functionally analyze large gene lists. Genome Biol 8: R183, 2007.

12. Kanehisa M, Sato Y, Kawashima M, Furumichi M and Tanabe M: KEGG as a reference resource for gene and protein annotation. Nucleic Acids Res 44 (D1): D457-D462, 2016.

13. Pinoli P, Chicco D and Masseroli M: Computational algorithms to predict gene ontology annotations. BMC Bioinformatics 16 (Suppl 6): S4, 2015.

14. Szklarczyk D, Franceschini A, Wyder S, Forslund K, Heller D, Huerta-Cepas J, Simonovic M, Roth A, Santos A, Tsafou KP, et al: STRING v10: Protein-protein interaction networks, integrated over the tree of life. Nucleic Acids Res 43 (Database issue) D447-D452, 2015.

15. Su G, Morris JH, Demchak B and Bader GD: Biological network exploration with Cytoscape 3. Curr Protoc Bioinformatics 47: 8.13.1-24, 2014.

16. Bandettini WP, Kellman P, Mancini C, Booker OJ, Vasu S, Leung SW, Wilson JR, Shanbhag SM, Chen MY and Arai AE: Multi contrast delayed enhancement (MCODE) improves detection of subendocardial myocardial infarction by late gadolinium enhancement cardiovascular magnetic resonance: A clinical validation study. J Cardiovasc Magn Reson 14: 83, 2012.

17. Gao J, Aksoy BA, Dogrusoz U, Dresdner G, Gross B, Sumer SO, Sun Y, Jacobsen A, Sinha R, Larsson E, et al: Integrative analysis of complex cancer genomics and clinical profiles using the cBioPortal. Sci Signal 6: pl1, 2013.

18. Cerami E, Gao J, Dogrusoz U, Gross BE, Sumer SO, Aksoy BA, Jacobsen A, Byrne CJ, Heuer ML, Larsson E, et al: The cBio cancer genomics portal: An open platform for exploring multidimensional cancer genomics data. Cancer Discov 2: 401-404, 2012.

19. Rosenbloom KR, Armstrong J, Barber GP, Casper J, Clawson H, Diekhans M, Dreszer TR, Fujita PA, Guruvadoo L, Haeussler M, et al: The UCSC Genome Browser database: 2015 update. Nucleic Acids Res 43 (Database Issue): D670-D681, 2015.

20. Rhodes DR, Yu J, Shanker K, Deshpande N, Varambally R, Ghosh D, Barrette T, Pandey A and Chinnaiyan AM: ONCOMINE: A cancer microarray database and integrated data-mining platform. Neoplasia 6: 1-6, 2004.

21. Cromer A, Carles A, Millon R, Ganguli G, Chalmel F, Lemaire F, Young J, Dembélé D, Thibault C, Muller D, et al: Identification of genes associated with tumorigenesis and metastatic potential of hypopharyngeal cancer by microarray analysis. Oncogene 23 : 2484-2498, 2004.

22. Estilo CL, O-charoenrat P, Talbot S, Socci ND, Carlson DL, Ghossein R, Williams T, Yonekawa Y, Ramanathan Y, Boyle JO, et al: Oral tongue cancer gene expression profiling: Identification of novel potential prognosticators by oligonucleotide microarray analysis. BMC Cancer 9: 11, 2009.

23. Ginos MA, Page GP, Michalowicz BS, Patel KJ, Volker SE, Pambuccian SE, Ondrey FG, Adams GL and Gaffney PM: Identification of a gene expression signature associated with recurrent disease in squamous cell carcinoma of the head and neck. Cancer Res 64: 55-63, 2004.
24. He H, Jazdzewski K, Li W, Liyanarachchi S, Nagy R, Volinia S, Calin GA, Liu CG, Franssila K, Suster S, et al: The role of microRNA genes in papillary thyroid carcinoma. Proc Natl Acad Sci USA 102: 19075-19080, 2005.

25. Peng CH, Liao CT, Peng SC, Chen YJ, Cheng AJ, Juang JL, Tsai CY, Chen TC, Chuang YJ, Tang CY, et al: A novel molecular signature identified by systems genetics approach predicts prognosis in oral squamous cell carcinoma. PLoS One 6: e23452, 2011

26. Pyeon D, Newton MA, Lambert PF, den Boon JA, Sengupta S, Marsit CJ, Woodworth CD, Connor JP, Haugen TH, Smith EM, et al: Fundamental differences in cell cycle deregulation in human papillomavirus-positive and human papillomavirus-negative head/neck and cervical cancers. Cancer Res 67: 4605-4619, 2007.

27. Ye H, Yu T, Temam S, Ziober BL, Wang J, Schwartz JL, Mao L, Wong DT and Zhou X: Transcriptomic dissection of tongue squamous cell carcinoma. BMC Genomics 9: 69, 2008.

28. Giordano TJ, Au AY, Kuick R, Thomas DG, Rhodes DR, Wilhelm KJ Jr, Vinco M, Misek DE, Sanders D, Zhu Z, et al: Delineation, functional validation, and bioinformatic evaluation of gene expression in thyroid follicular carcinomas with the PAX8-PPARG translocation. Clin Cancer Res 12: 1983-1993, 2006.

29. Vasko V,Espinosa AV, Scouten W, He H, Auer H,Liyanarachchi S, Larin A, Savchenko V, Francis GL, de la Chapelle A, et al: Gene expression and functional evidence of epithelial-to-mesenchymal transition in papillary thyroid carcinoma invasion. Proc Natl Acad Sci USA 104: 2803-2808, 2007.

30. Forastiere A, Koch W, Trotti A and Sidransky D: Head and neck cancer. N Engl J Med 345: 1890-900, 2001

31. Bozec A, Ilie M, Dassonville O, Long E, Poissonnet G, Santini J, Chamorey E,Ettaiche M,Chauviere D,Peyrade F, et al: Significance of circulating tumor cell detection using the Cell search system in patients with locally advanced head and neck squamous cell carcinoma. Eur Arch Otorhinolaryngol 270: 2745-2749, 2013.

32. Rettig EM and D'Souza G: Epidemiology of head and neck cancer. Surg Oncol Clin N Am 24: 379-396, 2015.

33. Marullo R, Werner E, Zhang H, Chen GZ, Shin DM and Doetsch PW: HPV16 E6 and E7 proteins induce a chronic oxidative stress response via NOX2 that causes genomic instability and increased susceptibility to DNA damage in head and neck cancer cells. Carcinogenesis 36: 1397-1406, 2015.

34. Boscolo-Rizzo P,Zorzi M, Del Mistro A, Da Mosto MC, Tirelli G, Buzzoni C, Rugge M, Polesel J and Guzzinati S; AIRTUM Working Group: The evolution of the epidemiological landscape of head and neck cancer in Italy: Is there evidence for an increase in the incidence of potentially HPV-related carcinomas? PLoS One 13: e0192621, 2018

35. Cheraghlou S, Torabi SJ, Husain ZA, Otremba MD, Osborn HA, Mehra S, Yarbrough WG, Burtness BA and Judson BL: HPV status in unknown primary head and neck cancer: Prognosis and treatment outcomes. Laryngoscope 129: 684-691, 2019.

36. Kreimer AR, Clifford GM, Boyle P and Franceschi S: Human papillomavirus types in head and neck squamous cell carcinomas worldwide: A systematic review. Cancer Epidemiol Biomarkers Prev 14: 467-475, 2005

37. Wu X, Cao W, Wang X, Zhang J, Lv Z, Qin X, Wu Y and Chen W: TGM3, a candidate tumor suppressor gene, contributes to human head and neck cancer. Mol Cancer 12: 151, 2013.

38. Masui T, Ota I, Itaya-Hironaka A, Takeda M, Kasai T, Yamauchi A, Sakuramoto-Tsuchida S, Mikami S, Yane K, Takasawa S and Hosoi H: Expression of REG III and prognosis in head and neck cancer. Oncol Rep 30: 573-578, 2013.

39. Andratschke M, Hagedorn $\mathrm{H}$ and Nerlich A: Expression of the epithelial cell adhesion molecule and cytokeratin 8 in head and neck squamous cell cancer: A comparative study. Anticancer Res 35: 3953-3960, 2015.

40. Squarize CH, Castilho RM, Abrahao AC, Molinolo A, Lingen MW and Gutkind JS: PTEN deficiency contributes to the development and progression of head and neck cancer. Neoplasia 15: 461-471, 2013.

41. Gross AM, Orosco RK, Shen JP, Egloff AM, Carter H, Hofree M, Choueiri M, Coffey CS, Lippman SM, Hayes DN, et al: Multi-tiered genomic analysis of head and neck cancer ties TP53 mutation to 3p loss. Nat Genet 46: 939-943, 2014.

42. Psyrri A, Seiwert TY and Jimeno A: Molecular pathways in head and neck cancer: EGFR, PI3K, and more. Am Soc Clin Oncol Educ Book: 246-255, 2013.

43. Mahjabeen I, Baig RM, Masood N, Sabir M, Inayat U, Malik FA and Kayani MA: Genetic variations in XRCC1 gene in sporadic head and neck cancer (HNC) patients. Pathol Oncol Res 19: 183-188, 2013. 
44. Boeckx C, Weyn C, Vanden Bempt I, Deschoolmeester V, Wouters A, Specenier P, Van Laer C, Van den Weyngaert D, Kockx M, Vermorken JB, et al: Mutation analysis of genes in the EGFR pathway in Head and Neck cancer patients: Implications for anti-EGFR treatment response. BMC Res Notes 7: 337, 2014

45. Gilkes DM, Semenza GL and Wirtz D: Hypoxia and the extracellular matrix: Drivers of tumour metastasis. Nat Rev Cancer 14: 430-439, 2014.

46. Malik R, Lelkes PI and Cukierman E: Biomechanical and biochemical remodeling of stromal extracellular matrix in cancer. Trends Biotechnol 33: 230-236, 2015.

47. Trulsson M, Yu H, Gisselsson L, Chao Y, Urbano A, Aits S, Mossberg AK and Svanborg C: HAMLET binding to $\alpha$-actinin facilitates tumor cell detachment. PLoS One 6: e17179, 2011.

48. Zhang HJ, Tao J, Sheng L, Hu X, Rong RM, Xu M and Zhu TY: Twist 2 promotes kidney cancer cell proliferation and invasion by regulating ITGA6 and CD44 expression in the ECM-receptor interaction pathway. Onco Targets Ther 9: 1801-1812, 2016.

49. Eke I and Cordes N: Focal adhesion signaling and therapy resistance in cancer. Semin Cancer Biol 31: 65-75, 2015.

50. Blackstone BN, Li R, Ackerman WT, Ghadiali SN, Powell HM and Kniss DA: Myoferlin depletion elevates focal adhesion kinase and paxillin phosphorylation and enhances cell-matrix adhesion in breast cancer cells. Am J Physiol Cell Physiol 308: C642-C649, 2015.

51. Johnson AL, Edson KZ, Totah RA and Rettie AE: Cytochrome P450 $\omega$-hydroxylases in inflammation and cancer. Adv Pharmacol 74: 223-262, 2015.

52. Ravegnini G, Sammarini G, Hrelia P and Angelini S: Key genetic and epigenetic mechanisms in chemical carcinogenesis. Toxicol Sci 148: 2-13, 2015.

53. Van Damme J, Rampart M, Conings R, Decock B, Van Osselaer N, Willems J and Billiau A: The neutrophil-activating proteins interleukin 8 and beta-thromboglobulin: In vitro and in vivo comparison of NH2-terminally processed forms. Eur J Immunol 20: 2113-2118, 1990.

54. Lo MC, Yip TC, Ngan KC, Cheng WW, Law CK, Chan PS Chan KC, Wong CK, Wong RN, Lo KW, et al: Role of MIF/CXCL8/CXCR2 signaling in the growth of nasopharyngeal carcinoma tumor spheres. Cancer Lett 335: 81-92, 2013.

55. Chan LP, Wang LF, Chiang FY, Lee KW, Kuo PL and Liang CH: IL-8 promotes HNSCC progression on CXCR $1 / 2$-meidated NOD1/RIP2 signaling pathway. Oncotarget 7: 61820-61831, 2016.

56. Christofakis EP, Miyazaki H, Rubink DS and Yeudall WA: Roles of CXCL8 in squamous cell carcinoma proliferation and migration. Oral Oncol 44: 920-926, 2008.

57. Curry JM, Sprandio J, Cognetti D, Luginbuhl A, Bar-ad V, Pribitkin E and Tuluc M: Tumor microenvironment in head and neck squamous cell carcinoma. Semin Oncol 41: 217-234, 2014.

58. Fang W, Ye L, Shen L, Cai J, Huang F, Wei Q, Fei X, Chen X, Guan H, Wang W, et al: Tumor-associated macrophages promote the metastatic potential of thyroid papillary cancer by releasing CXCL8. Carcinogenesis 35: 1780-1787, 2014

59. Tominaga K, Yoshimoto T, Torigoe K, Kurimoto M, Matsui K, Hada T, Okamura $\mathrm{H}$ and Nakanishi K: IL-12 synergizes with IL-18 or IL-1beta for IFN-gamma production from human T cells. Int Immunol 12: 151-160, 2000.

60. Stanam A, Gibson-Corley KN, Love-Homan L, Ihejirika N and Simons AL: Interleukin-1 blockade overcomes erlotinib resistance in head and neck squamous cell carcinoma. Oncotarget 7: 76087-76100, 2016.

61. Kim HS, Kwon HJ, Jung I, Yun MR, Ahn MJ, Kang BW, Sun JM, Kim SB, Yoon DH, Park KU, et al: Phase II clinical and exploratory biomarker study of dacomitinib in patients with recurrent and/or metastatic squamous cell carcinoma of head and neck. Clin Cancer Res 21: 544-552, 2015.

62. Kwon CH, Park HJ, Choi JH, Lee JR, Kim HK, Jo HJ, Kim HS, Oh N, Song GA and Park DY: Snail and serpinA1 promote tumor progression and predict prognosis in colorectal cancer. Oncotarget 6: 20312-20326, 2015 .

63. Kawahara R, Bollinger JG, Rivera C, Ribeiro AC, Brandão TB Paes Leme AF and MacCoss MJ: A targeted proteomic strategy for the measurement of oral cancer candidate biomarkers in human saliva. Proteomics 16: 159-173, 2016.

64. Qu T, Li YP, Li XH and Chen Y: Identification of potential biomarkers and drugs for papillary thyroid cancer based on gene expression profile analysis. Mol Med Rep 14: 5041-5048, 2016.

65. Vierlinger K, Mansfeld MH, Koperek O, Nöhammer C, Kaserer K and Leisch F: Identification of SERPINA1 as single marker for papillary thyroid carcinoma through microarray meta analysis and quantification of its discriminatory power in independent validation. BMC Med Genomics 4: 30, 2011.
66. Fialka F, Gruber RM, Hitt R, Opitz L, Brunner E, Schliephake H and Kramer FJ: CPA6, FMO2, LGI1, SIAT1 and TNC are differentially expressed in early- and late-stage oral squamous cell carcinoma-a pilot study. Oral Oncol 44: 941-948, 2008.

67. Renkonen S, Heikkilä P, Haglund C, Mäkitie AA and Hagström J: Tenascin-C, GLUT-1, and syndecan-2 expression in juvenile nasopharyngeal angiofibroma: Correlations to vessel density and tumor stage. Head Neck 35: 1036-1042, 2013.

68. Qiu F, Sun R, Deng N, Guo T, Cao Y, Yu Y, Wang X, Zou B, Zhang S, Jing T, et al: $\mathrm{miR}-29 \mathrm{a} / \mathrm{b}$ enhances cell migration and invasion in nasopharyngeal carcinoma progression by regulating SPARC and COL3A1 gene expression. PLoS One 10: e0120969, 2015.

69. Suresh A, Vannan M, Kumaran D, Gümüs ZH, Sivadas P, Murugaian EE, Kekatpure V, Iyer S, Thangaraj K and Kuriakose MA: Resistance/response molecular signature for oral tongue squamous cell carcinoma. Dis Markers 32: 51-64, 2012.

70. Sepiashvili L, Hui A, Ignatchenko V, Shi W, Su S, Xu W, Huang SH, O'Sullivan B, Waldron J, Irish JC, et al: Potentially novel candidate biomarkers for head and neck squamous cell carcinoma identified using an integrated cell line-based discovery strategy. Mol Cell Proteomics 11: 1404-1415, 2012.

71. Gu M, Guan J, Zhao L, Ni K, Li X and Han Z: Correlation of ECM1 expression level with the pathogenesis and metastasis of laryngeal carcinoma. Int J Clin Exp Pathol 6: 1132-1137, 2013.

72. Meng XY, Liu J, Lv F, Liu MQ and Wan JM: Study on the correlation between extracellular matrix protein-1 and the growth metastasis and angiogenesis of laryngeal carcinoma. Asian Pac J Cancer Prev 16: 2313-2316, 2015.

73. Pavón MA, Arroyo-Solera I, Céspedes MV, Casanova I, León X and Mangues R: uPA/uPAR and SERPINE1 in head and neck cancer: Role in tumor resistance, metastasis, prognosis and therapy. Oncotarget 7: 57351-57366, 2016.

74. Pavón MA, Arroyo-Solera I, Téllez-Gabriel M, León X, Virós D, López M, Gallardo A, Céspedes MV, Casanova I, López-Pousa A, et al: Enhanced cell migration and apoptosis resistance may underlie the association between high SERPINE1 expression and poor outcome in head and neck carcinoma patients. Oncotarget 6: 29016-29033, 2015.

75. Van Tubergen EA, Banerjee R, Liu M, Vander Broek R, Light E, Kuo S, Feinberg SE, Willis AL, Wolf G, Carey T, et al: Inactivation or loss of TTP promotes invasion in head and neck cancer via transcript stabilization and secretion of MMP9, MMP2, and IL-6. Clin Cancer Res 19: 1169-1179, 2013.

76. Pietruszewska W, Bojanowska-Poźniak K and Kobos J: Matrix metalloproteinases MMP1, MMP2, MMP9 and their tissue inhibitors TIMP1, TIMP2, TIMP3 in head and neck cancer: An immunohistochemical study. Otolaryngol Pol 70: 32-43, 2016.

77. Zhang C, Li C, Zhu M,Zhang Q, Xie Z, Niu G, Song X, Jin L, Li G and Zheng H: Meta-analysis of MMP2, MMP3, and MMP9 promoter polymorphisms and head and neck cancer risk. PLoS One 8: e62023, 2013.

78. Vincent-Chong VK, Salahshourifar I, Karen-Ng LP, Siow MY, Kallarakkal TG, Ramanathan A, Yang YH, Khor GH, Rahman ZA, Ismail SM, et al: Overexpression of MMP13 is associated with clinical outcomes and poor prognosis in oral squamous cell carcinoma. ScientificWorldJournal 2014: 897523, 2014

79. Pradhan-Palikhe P, Vesterinen T, Tarkkanen J, Leivo I, Sorsa T, Salo T and Mattila PS: Plasma level of tissue inhibitor of matrix metalloproteinase-1 but not that of matrix metalloproteinase- 8 predicts survival in head and neck squamous cell cancer. Oral Oncol 46: 514-518, 2010.

80. Huang CF, Yu GT, Wang WM, Liu B and Sun ZJ: Prognostic and predictive values of SPP1, PAI and caveolin-1 in patients with oral squamous cell carcinoma. Int J Clin Exp Pathol 7: 6032-6039, 2014.

81. Aquino G, Sabatino R, Cantile M, Aversa C, Ionna F, Botti G, La Mantia E, Collina F, Malzone G, Pannone G, et al: Expression analysis of SPARC/osteonectin in oral squamous cell carcinoma patients: From saliva to surgical specimen. Biomed Res Int 2013: 736438, 2013.

82. Li L, Lei Q, Zhang S, Kong L and Qin B: Screening and identification of key biomarkers in hepatocellular carcinoma: Evidence from bioinformatic analysis. Oncol Rep 38: 2607-2618, 2017.

83. Saha SK, Jeong Y, Cho S and Cho SG: Systematic expression alteration analysis of master reprogramming factor OCT4 and its three pseudogenes in human cancer and their prognostic outcomes. Sci Rep 8: 14806, 2018.

84. Yang Y, Dong X, Xie B, Ding N, Chen J, Li Y, Zhang Q, Qu H and Fang X: Databases and web tools for cancer genomics study. Genomics Proteomics Bioinformatics 13: 46-50, 2015.

This work is licensed under a Creative Commons Attribution-NonCommercial-NoDerivatives 4.0 International (CC BY-NC-ND 4.0) License. 